Science, Technology and Development 34 (2): 101-104, 2015

ISSN 0254-6418 / DOI: 10.3923/std.2015.101.104

(C) 2015 Pakistan Council for Science and Technology

\title{
Statistical Tyre/Road Noise Modeling in Hong Kong on Polymer Modified Friction Course
}

\author{
K.L. Mak and W.K. Loh \\ Hong Kong Community College, Hong Kong, China
}

\begin{abstract}
Based on the Close Proximity (CPX) method specified in ISO/DIS 11819-2, we recorded and analyzed the instantaneous tyre/road sound pressure levels with 4 road sections that are constructed with the same pavement surfacing materials, that is, polymer modified friction course (PMFC). A total of 488 segments were made in urban areas with a pair of Standard Road Test Tyre (SRTT). We tried to relate the tyre/road noise with the instantaneous acceleration, vehicle speed, road temperature, road gradient and road surface age to develop a multi-variants model. It was subsequently found that a simple tyre/road noise model linking driving speed and acceleration is the best model. The model provides an easy way to estimate the instantaneous tyre/road noise level. As the tyre/road noise is becoming more dominant component of the road traffic noise, our proposed model has the potential to improve the current practice in estimating the road traffic noise by introducing the interaction effect to statistical tyre/road noise model.
\end{abstract}

Key words: Tyre/road noise, close proximity, statistical noise modeling

\section{INTRODUCTION}

Road traffic noise comprises three main components, i.e., the vehicle engine and exhaust noise, the aerodynamic noise and the tyre/road noise. The engine and exhaust noise depends on the power demand required of the engine during operation and is higher at accelerating mode. The design of the engine however has improved over the years and becomes quieter over evolution of the vehicle design technology. The migration to electric vehicles in the coming decades will gradually reduce the vehicles propelled by engines on the road. In order to improve fuel efficiency of vehicles, car manufacturers have been improving the aerodynamics of vehicles. Subsequently, the noise generated by vehicle movements has also gradually reduced over the years. As engine noise reduces, tyre noise has become one of the major sources of passenger car noise nowadays. Tyre/road noise is becoming a significant contributor in the local environment. In this paper, the characteristics of tyre/road noise are studied in order to find ways to reduce the noise emitted by the interaction between vehicle tyre and road surface. According to Li et al. (2009), many factors affect the amount of tyre/road noise emissions. These factors include vehicle speed, acceleration, road gradient, thickness of surface layer and the age of road surface. It is generally accepted that traffic noise levels are affected by the road gradient. Johnson and Saunders (1968) was fist concluded that the effect of gradient depends upon the percentage of heavy vehicles and predicted increases of up to $12 \mathrm{~dB}$ (A) for a gradient of 1 in 8 . However, later research suggested the estimation was too high and under normalized conditions the increase was only of the order of $4 \mathrm{~dB}$ (A). Road gradient was first applied in noise model in the 1952 Handbook of acoustic Noise control (WADC., 1952), correction were included for gradients. Anonymous (1975) was further included road gradient for finding L10 value. MITHRA also further consider road gradient as one of the parameters in the algorithm for traffic noise estimation. EMPA (1987) and O'Boy and Dowling (2009) tried to model tyre/road noise by using the finite element method. The model, however, has limitation to mimic the noise generated in the real road conditions. A more practical approach to measure the on-road tyre/road noise directly is being practiced in order to understand the characteristics of road noise. Mak and Hung (2014) applied statistical method on modeling tyre/road noise on fiction course material, however, rarely researches try to investigate the interaction effect between variable. Therefore, in this study, we aimed to investigate the interaction effect between variables.

ISO/DIS 11819-2 (2012) on the close proximity (CPX) tyre/road noise measurement method specifies placing two mandatory microphones close to a rolling tyre and road contact surface to record the sound pressure level. A CPX tyre/road noise measurement vehicle was developed by Hung et al. (2007) in Hong Kong and has been used to measure the tyre/road noise of many road surfaces. Simultaneously, this CPX vehicle also measures the instantaneous speed-time profiles of the vehicle. The data set enables the analysis of the relationship between tyre/road noise and instantaneous driving pattern. 
Sci. Technol. Dev., 34 (2): 101-104, 2015

\section{MATERIALS AND METHODS}

The development of our proposed statistical tyre/road noise model started from the principal component analysis on urban driving condition and road surface condition variables. Statistical principal component analysis was used for identify redundant variables and to identify the most important components and also quantify the percentage of variation represented by each component. The principal components results can indicate if interaction effects exist between variables. For a multiple significant coefficient factors component, it represents the interaction effect that exists between corresponding factors. Interaction effect between corresponding factors should be investigated further to identify their relationship with tyre/road noise.

After identified the existence of interaction effects between principal factors, cluster analysis on tyre/road noise levels with the pre-defined principal factors has been applied to generate a three-dimensional matrix in order to identifying the relationship of the interaction effects between factors. Cluster analysis classified a set of observations into two or more mutually exclusive unknown groups based on combinations of interval variables. The purpose of cluster analysis is to discover a system of organizing observations. An instantaneous and small interval range three-dimensional tyre/road noise matrix is developed by applying cluster analysis. The corresponding tyre/road noise is calculated and placed in each cell of two pre-defined principal factors, with one being the row and the other one being the column of the matrix. The matrix can help with quantify the interaction effects.

Lastly, statistical stepwise multiple regression analysis was applied on the urban driving behaviour factor for overall tyre/road noise level. Besides identifying the principal tyre/road noise impacting factors, the regression model can also be used to quantify the contribution of each factor.

The statistical tyre/road noise prediction model can express as follow:

$$
\mathrm{SPL}_{\text {freequency }}=\sum \alpha_{\mathrm{i}} \mathrm{X}_{\mathrm{i}}+\sum \beta_{\mathrm{i}} \mathrm{X}_{\mathrm{i}} \mathrm{X}_{\mathrm{j}}
$$

$\alpha_{\mathrm{i}} \quad=$ Coefficient of parameter $\mathrm{X}_{\mathrm{i}}$

$\mathrm{X}_{\mathrm{i}}, \mathrm{X}_{\mathrm{j}}=$ Parameter of urban driving condition

$\beta_{\mathrm{i}}=$ Coefficient of the interaction effect between parameters $\mathrm{X}_{\mathrm{i}}$ and $\mathrm{X}_{\mathrm{j}}$

Data collection: The CPX method in measuring tyre/road noise as specified in the ISO/DIS 11819-2 was employed. This method uses two mandatory microphones; one positioned at $200 \mathrm{~mm}$ from the tyre side wall and the other at $100 \mathrm{~mm}$ above the surface. At+ and $-45^{\circ}$ with respect to the centre of the contact patch, the tyre/road noise is to be measured. The CPX method enhances the ability to determine the noise characteristics of the road surface at almost any arbitrary site. Most importantly, the CPX method allows tyre/road noise measurement on the in-use traffic roads and hence the real situation of the tyre/road noise influence can be measured. A CPX trailer towed by a light duty vehicle has been built to measure the tyre/road noise in Hong Kong. This CPX assembly has been certified and details were reported by the authors (Hung et al., 2008).

To record the travelling speed of the CPX vehicle for speed monitoring and speed correction in data analysis, a Microstar Speed Sensor from Corrsys-datron is adopted. Mak et al. (2011) applied a microwave speed sensor on the CPX vehicle to measure instantaneous speed in parallel with the tyre/road noise measurement. The microwave antenna is fixed at the side of the CPX vehicle. The data acquisition system, power supply system and a lap-top computer are placed in the vehicle.

Polymer Modified Friction Course (PMFC) with a thickness of $30 \mathrm{~mm}$ and the maximum chipping size of $10 \mathrm{~mm}$ is selected for study in this survey. The survey involves driving the CPX vehicle repeatedly along these selected road sections.

A total of 488 segments along the 4 selected road sections were made in urban areas with a pair of SRTT, the pavement surface age, road gradient, air temperature and road temperature were also recorded for analysis.

\section{RESULTS}

On every trip, the data for both tyre/road noise and speed were recorded on a second-by-second basis. These constituted the database for the analysis of spatial differences in driving characteristics. Besides driving behaviour, the pavement surface age, road gradient and sampling road temperature were also recorded for analysis.

According to our proposed analytical steps described in above, the linear relationships between tyre/road noise in terms of sound pressure level and all variables by different road surface type were first tested and the results are shown in Table 1. The significance test on Pearson's correlation coefficients showed that most of the variables had significant linear relationships to SPL, except for road surface age. Besides, both correlation values indicated strong relationships. Pearson correlation together with the significance test on Pearson correlation for each variable was calculated as shown in Table 2. It can be observed that most of the variables do not have significant linear relationships with other variables, except for road temperature and air temperature. 
Sci. Technol. Dev., 34 (2): 101-104, 2015

Table 1: Correlation table between SPL and other variables

\begin{tabular}{lcccc}
\hline Correlation parameters & Gradient $(\tan \theta)$ & Vehicle speed $\left(\mathrm{m} \mathrm{sec}^{-1}\right)$ & Absolute vehicle acceleration $\left(\mathrm{m} \mathrm{sec}^{-2}\right)$ & Road temperature $\left({ }^{\circ} \mathrm{C}\right)$ \\
\hline Left mic $(\mathrm{dB})$ & 0.635 & 0.838 & 0.795 & 0.711 \\
Right mic $(\mathrm{dB})$ & 0.617 & 0.825 & 0.763 & 0.693 \\
\hline
\end{tabular}

Table 2: Correlation table between variables

\begin{tabular}{lccc}
\hline Correlation parameters & Gradient $(\tan \theta)$ & Vehicle speed $\left(\mathrm{m} \mathrm{sec}^{-1}\right)$ & Absolute vehicle acceleration $\left(\mathrm{m} \mathrm{sec}{ }^{-2}\right)$ \\
\hline Vehicle speed $\left(\mathrm{m} \mathrm{sec}^{-1}\right)$ & 0.142 & & \\
Absolute vehicle acceleration $\left(\mathrm{m} \mathrm{sec}^{-2}\right)$ & 0.231 & 0.354 & 0.204 \\
Road temperature $\left({ }^{\circ} \mathrm{C}\right)$ & 0.123 & 0.027 & \\
\hline
\end{tabular}

Table 3: Eigenvalues and percentage of variance represented by corresponding components

\begin{tabular}{lcr}
\hline Components & Eigen values & Variance (\%) \\
\hline 1 & 1.715 & 38.26 \\
2 & 1.531 & 34.13 \\
3 & 1.065 & 23.74 \\
4 & 0.173 & 3.86 \\
\hline
\end{tabular}

Table 4: Result of principal components analysis

\begin{tabular}{llcc}
\hline & Components & & \multicolumn{1}{c}{ 2 } \\
\hline Parameters & -1 & 0.015 & 0.148 \\
Road gradient & 0.120 & -0.226 & 0.173 \\
Road temperature & 0.007 & 0.302 & $0.645^{*}$ \\
Vehicle speed & $0.918^{*}$ & $0.716^{*}$ & $0.548^{*}$ \\
Vehicle acceleration & 0.309 &
\end{tabular}

*Coefficient is significant at the 0.05 level

Table 5: Coefficient of each statistical model together with the R-square value

\begin{tabular}{|c|c|c|}
\hline \multirow[b]{2}{*}{ Parameters } & \multicolumn{2}{|l|}{ Overall SPL (dB) } \\
\hline & Left mic & Right mic \\
\hline Constant & 90.212 & 89.729 \\
\hline Vehicle speed $\left(\mathrm{m} \mathrm{sec}^{-1}\right)$ & 0.759 & 0.724 \\
\hline Road temperature $\left({ }^{\circ} \mathrm{C}\right)$ & Not significant & Not significant \\
\hline Absolute acceleration $\left(\mathrm{m} \mathrm{sec}^{-1}\right)$ & 1.618 & 1.514 \\
\hline Interaction effect (speed X absolute acceleration) & 0.073 & 0.096 \\
\hline Gradient & Not significant & Not significant \\
\hline$\underline{\text { R-square }}$ & 0.839 & 0.731 \\
\hline
\end{tabular}

The corresponding components are shown in Table 3. The component analysis was carried out on the data set and the eigenvalues and percentage of variance represented by the corresponding components are shown in Table 4. The result showed that three components had eigenvalues greater than one, so these three components were selected as the principal factors in our data set. Varimax with Kaiser normalization was applied for rotation methods on extracting the principal components.

After Varimax rotation, three components were extracted by principal component analysis. The first component was dominated by the factor vehicle speed, which was also the only significant coefficient in the first component. This means that vehicle speed can represent $38.26 \%$ of the overall variation. The second component was dominated by vehicle acceleration only, which represented $34.13 \%$ of overall variation. The last component had two significant coefficients which were vehicle speed and vehicle acceleration. The last component represented $23.74 \%$ of overall variation. As the second component covered two significant factors, it represented an interaction effect that existed between these significant factors. To conclude, $96.14 \%$ of the overall variation could be represented by the suggested three components.

As the results of the principal component analysis showed that vehicle speed and vehicle acceleration have a single principal effect, further analysis on the impact of the corresponding factors was undertaken. An interaction effect between vehicle speed and vehicle acceleration was suggested by the result of the principal component analysis. Therefore, the effect of the interaction between vehicle speed and vehicle acceleration on tyre/road noise was investigated further.

We further try to develop a tyre/road noise model with overall SPL. The tyre/road noise (SPL) was considered as the dependent variable and the five parameters (i.e., vehicle speed, road gradient, absolute acceleration, road temperature, interact effect between vehicle speed and absolute acceleration) were independent variables in this regression analysis. The coefficient of each statistical model together with the $\mathrm{R}$-square value is shown in Table 5. Furthermore, the residuals of all models shown in Table 5 have fulfilled the 
Sci. Technol. Dev., 34 (2): 101-104, 2015

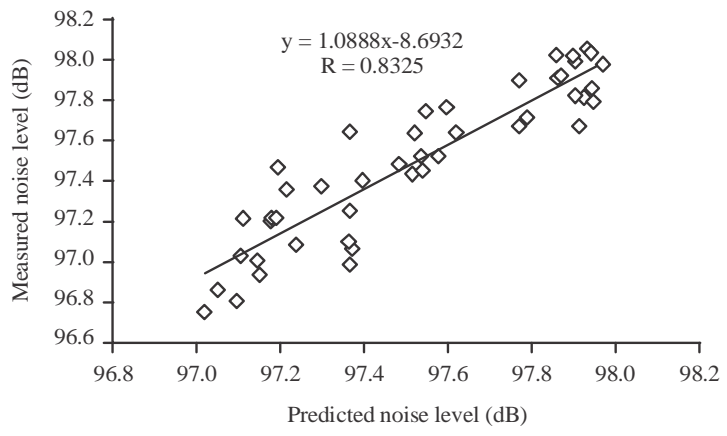

Fig. 1: Measured and predicted noise level (dB)

requirement of independent, normal distribution with zero mean and constant variance. The results show that vehicle speed, absolute acceleration and the interaction effect between vehicle speed and absolute acceleration are particularly significant factors in the model. Relatively high R-square values, i.e., 0.839 and 0.731 are observed for left and right microphone, respectively.

Model verification: We validated the developed prediction model in this study using the data collected at another sampling site in Hong Kong in 2013 with same surface texture and tyre. Figure 1 indicated the comparison between measured and predicted noise level. Figure 1, indicted the comparison between measured and predicted noised levels at Hong Kong in the developed prediction model. From the result shown in Fig. 1, it indicated that the predicted values by the developed model in this study were very accurate in statistical point of view.

\section{CONCLUSION}

The tyre/road noise generation mechanism is so complicated that the influences or effects are not only from individual factors, but also a combination of two or more factors or even interaction effects. Also, the influence of each factor is hard to estimate since the travelling conditions of a vehicle will involve changes in these factors, such as speed, road surface materials as well as the tyres. Multiple regression analysis was applied to the data set and statistical tyre/road noise models were developed for urban driving conditions. The model showed that vehicle speed, absolute acceleration and the interaction effect between vehicle speed and absolute acceleration are the major factors in the tyre/road noise model. Verification was carried out in Hong Kong, a high accuracy was showed in our prediction model. The introduction of the interaction effect can help to improve the current tyre/road noise model and also provide a better and more complete picture of urban driving tyre/road noise.

\section{REFERENCES}

Anonymous, 1975. Calculation of road traffic noise. United Kingdom Department of the Environment and Welsh Office Joint Publication/HMSO, London.

EMPA., 1987. Modele de calcul de bruit du trafic routier pour ordinateur. 1 Ere Partie Manuel D'utilisation du Logiciel StL-86. L'Office Federal de la Protection de L'environnement, Berne.

Hung, W.T., W.G. Wong and C.F. Ng, 2008. Certification of a CPX trailer for measuring tyre/road noise in Hong Kong, CD ROM. Proceedings of Inter-Noise 2008: 37th International Congress and Exposition on Noise Control Engineering, October 26-29, 2008, Shanghai, China.

Hung, W.T., W.G. Wong, G. Watts and C.F. Ng, 2007. A report on tyre/road noise. Surveyon Low Noise Road Surfaces, EPD, December 2007.

ISO/DIS 11819-2, 2012. Acoustics-measurement of the influence of road surfaces on traffic noise-part 2. Final Draft of ISO/DIS 11819-2 CPX Method, ICS 17.140.30, December 20, 2012.

Johnson, D.R. and E.G. Saunders, 1968. The evaluation of noise from freely flowing road traffic. J. Sound Vibration, 7: 287-309.

Li, M., A. Molenaar, M. van de Ven and R. Huurman, 2009. New approach for modelling tyre/road noise. Proceeding of Inter-Noise Innovations in Practical Noise Control, August 23-26, 2009, Ottawa, Canada.

Mak, K.L. and W.T. Hung, 2014. Statistical tyre/road noise modeling in Hong Kong on friction course. Applied Acoust., 76: 24-27.

Mak, K.L., S.H. Lee, K.Y. Ho and W.T. Hung, 2011. Developing instantaneous tyre/road noise profiles: A note. Transp. Res. Part D: Transp. Environ., 16: 257-259.

O'Boy, D.J. and A.P. Dowling, 2009. Tyre/road interaction noise-Numerical noise prediction of a patterned tyre on a rough road surface. J. Sound Vibration, 323: 270-291.

WADC., 1952. Handbook of acoustic noise control. Wright Air Development Center (WADC), WADC Technical Report 52-204. 